\title{
Korean consumers' awareness of the risks of chemicals in daily consumer products
}

\author{
Seunghye Sim', Jeongsu Lee ${ }^{2}$, Yoonhee Uhm³ ${ }^{3}$ Soonbok Kim ${ }^{4}$, Eun Jeong Han ${ }^{1}$, KeunOh Choi ${ }^{1}$, \\ Junyeong Choi ${ }^{1}$, Q-man Ban ${ }^{5}$, Taeje Cho ${ }^{6}$, Augustine Yonghwi Kim, Dong II Lee ${ }^{8}$, Eunkyung Lim ${ }^{3 *}$ \\ and Young Joo Lee ${ }^{1 *}$ (D)
}

\begin{abstract}
Background: Recent tragic accidents due to the use of humidifier disinfectants have caused severe distrust and anxiety over chemicals in consumer products in Korea. Therefore, a survey was conducted to determine consumer opinions about the risk of everyday chemical products used in Korea to assess what information should be provided to consumers via risk communication systems.

Results: An online survey investigated the awareness of 10,000 Korean people regarding potentially harmful substances in consumer chemical products. Concern about the ingredients of chemical products was greatest for pesticides, air fresheners/deodorants, and cleaning agents. There was comparatively little concern about toiletries and personal care products. Respondents were aware of the presence of harmful substances from information on mass media and consumer/environmental organizations, and they also obtained information from ingredient lists and product packaging. Many participants thought that products made from natural materials and products with ecofriendly labeling did not contain harmful substances. Participants replied that they used potentially harmful products as little as possible to reduce the risk. Half of all respondents said that the manufacturers and retailers of products should take responsibility for reducing harmful substances in consumer products. Most respondents were not aware that they could make information disclosure requests for ingredients information.

Conclusion: There are numerous concerns about chemicals in consumer products, but many people still do not know exactly what risks they pose. There is a need to communicate information about the risks of chemicals using the media and methods that people can understand.
\end{abstract}

Keywords: Harmful chemical substance, Consumer chemical product, Consumer's awareness, K-REACH

\section{Background}

In the Republic of Korea, humidifier disinfectants that include biocidal ingredients have resulted in 6246 reported victims and 1375 deaths as of February 28, 2019, by causing pulmonary fibrosis [1-3]. There are

\footnotetext{
*Correspondence: lim@consumer.or.kr; yjlee@sejong.ac.kr

${ }^{1}$ Department of Integrated Bioscience and Biotechnology, College of Life Science, Sejong University, Kwangjingu, Kunjadong, Seoul 05006, South Korea

${ }^{3}$ Korea National Council of Consumer Organizations, SEOUL YWCA Bld.

\#701, 20, Myungdong11 gil, Jung-gu, Seoul, South Korea

Full list of author information is available at the end of the article
}

31 commercially available humidifier disinfectants, and they contain germicides, such as methylisothiazolinone/ chloromethylisothiazolinone, polyhexamethylene guanidine phosphate, and oligo(2-(2-ethoxy)-ethoxyethyl guanidinium chloride [2]. These agents exit the humidifier in water droplets and, as the water evaporates, they condense. These agents enter the respiratory system of humans via inhalation, which can lead to respiratory diseases, such as pulmonary fibrosis, asthma, and pneumonia, and can even affect the eyes, heart, skin, and liver. The main reason for this disaster was that no safety tests had been conducted to assess the effects on human 
health before and during the sale of these products. On February 15, 2019, the government arranged for compensation by enacting a special law to remedy humidifier disinfectant victims. In other incidents in Korea, pesticides such as fipronil, bifenthrin, and dichlorodiphenyltrichloroethane have been detected in eggs, and volatile organic compounds have been detected in disposable sanitary pads [4]. These incidents have raised concerns regarding exposure and damage caused by chemicals that are not recognized by the public, which have led to chemophobia, as an emerging societal issue $[5,6]$.

The Act on the Registration and Evaluation of Chemical Substances (K-REACH) is the Korean version of the European Registration, Evaluation, Authorization and Restriction of Chemicals (REACH) regulation. K-REACH originally aimed to manage the risks from chemical exposure by providing relevant information on intrinsic risks and guidance regarding safe use, such as by providing proper classification and labeling [7]. It was enforced first on January 1, 2015, and partly amended several times until Oct 16, 2018. Pursuant to the Act, any person who produces or imports over $1 \mathrm{t}$ of an existing chemical substance subject to registration, or $100 \mathrm{~kg}$ of a new chemical substance, should register that chemical with the Minister of Environment. In accordance with Section 2, Article 35 of the Act, if a product contains 'a substance subject to intensive control', when a consumer requests information, the person who transfers the product (e.g., manufacturer, importer, seller, or sub-user) must provide information, such as the product name as well as the name and concentration of the 'substance subject to intensive control', its purpose, and its restricted concentration [8]. The Act on Safety Control of Consumer Chemical Products and Biocides was enforced January 1, 2019 [9]. According to this Act, those who intend to manufacture or import products with safety notification criteria among the 35 consumer chemical products subject to safety verification must verify whether a product conforms to safety standards. In the case of products without safety criteria, such as disinfectants for humidifiers, data must be submitted on the use of such chemicals and must be approved by the Minister of Environment. Pursuant to Sections 1 and 2, Article 29 of the Act [9], information on biocidal substances and biocidal products approved by the Environment Minister must be disclosed, and the person who purchases a biocide-treated product (a product that uses a biocidal product for secondary purposes, such as removal of harmful organisms, in addition to its main purpose) may request that the manufacturer or importer of the product provide information about the biocidal agents used in that biocidetreated product (Section 1, Article 30) [9].
Everyday products contain many chemical ingredients, including preservatives in washing and cleaning agents, fragrances in personal care products, and plasticizers in plastic materials. According to European Union regulations, many substances in consumer products are classified as hazardous chemicals [10]. However, because there is an increasing number of chemicals [11], it is difficult to predict their effects on human health. There is also the issue of co-exposure to multiple chemicals in daily life, because multiple consumer products are used every day, and these products contain a variety of chemicals [12]. Even if each chemical ingredient is present at a safe level, the combination of chemicals could lead to health effects [13].

Given the nature of consumer products, chemicals found in such products come into close contact with consumers every day $[14,15]$. These chemicals present very different levels of risk depending on the product use pattern, which determines the extent of potential exposure $[16,17]$. In many cases, a lack of knowledge about chemical risks and failure to implement basic protection measures are the causes of exposure to hazardous chemicals [18]. In other words, people could avoid exposure to chemicals if they had access to accurate risk information. Hence, we carried out a survey to investigate how people perceive harmful substances in their daily chemical products and how information can be more appropriately provided to consumers.

\section{Methods}

\section{Survey content and analysis}

We conducted an online survey of 10,000 Korean consumers between March 25 and April 19, 2019. Respondents were distributed evenly according to gender and age class (Table 1). The survey included questions about the usage pattern of products; however, the focus of this study was on the opinion of consumers regarding the risk of using household products. The total number of questions, including questions for selecting respondents, was 31. The maximum number of questions a person can answer was 30 due to question C1 (logic of the questionnaire is presented in Additional file 1: Figure S1). Previously, a survey was conducted on 1000 Korean consumers regarding select product groups that are frequently used in each part of the home. In that study, household chemical products were classified into six groups by use: (1) laundry room, (2) kitchen, (3) bathroom and toilet, (4) living room, (5) personal care, (6) other items. Following the previous study, we asked about representative products from each of these groups, as well as pesticides. Respondents were asked about seven product groups, but the detailed analysis was conducted on six products, as we excluded 'other' products: 
Table 1 Study demographic characteristics. In total, 10,000 participants took the survey

\begin{tabular}{|c|c|c|}
\hline & Number & Percentage (\%) \\
\hline \multicolumn{3}{|l|}{ Gender } \\
\hline Male & 5000 & 50 \\
\hline Female & 5000 & 50 \\
\hline \multicolumn{3}{|l|}{ Age } \\
\hline $20-29$ & 1936 & 19.36 \\
\hline $30-39$ & 2070 & 20.7 \\
\hline $40-49$ & 2442 & 24.42 \\
\hline $50-59$ & 2431 & 24.31 \\
\hline Over 60 & 1121 & 11.21 \\
\hline \multicolumn{3}{|l|}{ Marital status } \\
\hline Married & 6296 & 62.96 \\
\hline Single & 3704 & 37.04 \\
\hline \multicolumn{3}{|l|}{ Number of family members } \\
\hline 1 & 934 & 9.34 \\
\hline 2 & 1807 & 18.07 \\
\hline 3 & 2778 & 27.78 \\
\hline 4 & 3594 & 35.94 \\
\hline Over 5 & 887 & 8.87 \\
\hline \multicolumn{3}{|l|}{ Child status } \\
\hline 1 or more & 5639 & 56.39 \\
\hline None & 657 & 6.57 \\
\hline Single & 3704 & 37.04 \\
\hline \multicolumn{3}{|l|}{ Number of minor children } \\
\hline None & 1715 & 17.15 \\
\hline 1 & 1923 & 19.23 \\
\hline 2 & 1751 & 17.51 \\
\hline Over 3 & 250 & 2.5 \\
\hline \multicolumn{3}{|l|}{ Household income } \\
\hline Less than 2 million won & 1018 & 10.18 \\
\hline 2-4 million won & 3286 & 32.86 \\
\hline 4-6 million won & 3413 & 34.13 \\
\hline Over 6 million won & 2283 & 22.83 \\
\hline \multicolumn{3}{|l|}{ Employment category } \\
\hline Homemaker & 1442 & 14.42 \\
\hline White-collar (management, office job) & 4211 & 42.11 \\
\hline $\begin{array}{l}\text { Blue-collar (sales service, production, } \\
\text { farming) }\end{array}$ & 1193 & 11.93 \\
\hline Professional, administrative position & 1078 & 10.78 \\
\hline Self-employed & 689 & 6.89 \\
\hline Student & 844 & 8.44 \\
\hline Inoccupation/etc. & 543 & 5.43 \\
\hline \multicolumn{3}{|l|}{ Body weight (kg) } \\
\hline Less than 50 & 898 & 8.98 \\
\hline $50-60$ & 2772 & 27.72 \\
\hline $60-70$ & 2815 & 28.15 \\
\hline $70-80$ & 2067 & 20.67 \\
\hline Over 80 & 1448 & 14.48 \\
\hline
\end{tabular}

Table 1 (continued)

\begin{tabular}{lcc}
\hline & Number & Percentage (\%) \\
\hline House area $\left(\mathrm{m}^{2}\right)$ & & \\
Less than 50 & 897 & 8.97 \\
$50-83$ & 2428 & 24.28 \\
$83-116$ & 4817 & 48.17 \\
Over 116 & 1858 & 18.58 \\
\hline
\end{tabular}

(1) laundry cleaning products, (2) cleaning agents, (3) toiletries, (4) air fresheners and deodorants, (5) personal care products, (6) pesticides. Questions about the degree of concern regarding the ingredients of each product group were asked on a five-point scale, while other questions were multiple choice. In addition, several questions offered the option to add text. The questionnaire was distributed in Korean and is included in Additional files in English (Additional file 2).

The confidence level in this study was $95 \pm 1.00 \%$, and we conducted a basic statistical analysis (analysis of variance, Tukey's test, $t$ test). The demographic variables were gender, age, marital status, number of family members, child status, household income, occupation category, body weight, and house area. The degree of concern for each product group was assessed based on a basic statistical analysis for all product groups and variables. The $\mathrm{p}$ values are listed in Additional file 1: Tables S1-S10.

\section{Results}

Pesticides elicited the greatest concern

among the substances in consumer chemical products

From the results of the survey that inquired about the participants' degree of concern regarding the substances in 6 consumer chemical product groups, the highest degree of concern was expressed for pesticides (mean $=4.14$ ) (Fig. 1). This was followed by laundry cleaning products (synthetic detergents, fabric softeners, and bleaches) $($ mean $=3.60)$, air fresheners and deodorants $($ mean $=3.57)$, cleaning agents $($ mean $=3.45)$, toiletries (shampoos, conditioners, body cleansers, etc.) $($ mean $=3.02)$, and personal care products (lotion, toner, hand lotion, etc.) $($ mean $=2.96)$.

Among the results for toiletries (shampoos, conditioners, body cleansers, etc.), females expressed a higher degree of concern $($ mean $=3.20)$ than males $($ mean $=2.85)$ (Fig. 1a). Compared to the concerns of unmarried participants $($ mean $=2.92)$, married participants were more concerned about the substances present in toiletries $($ mean $=3.08)$ (Fig. 1c). As for the number of family 


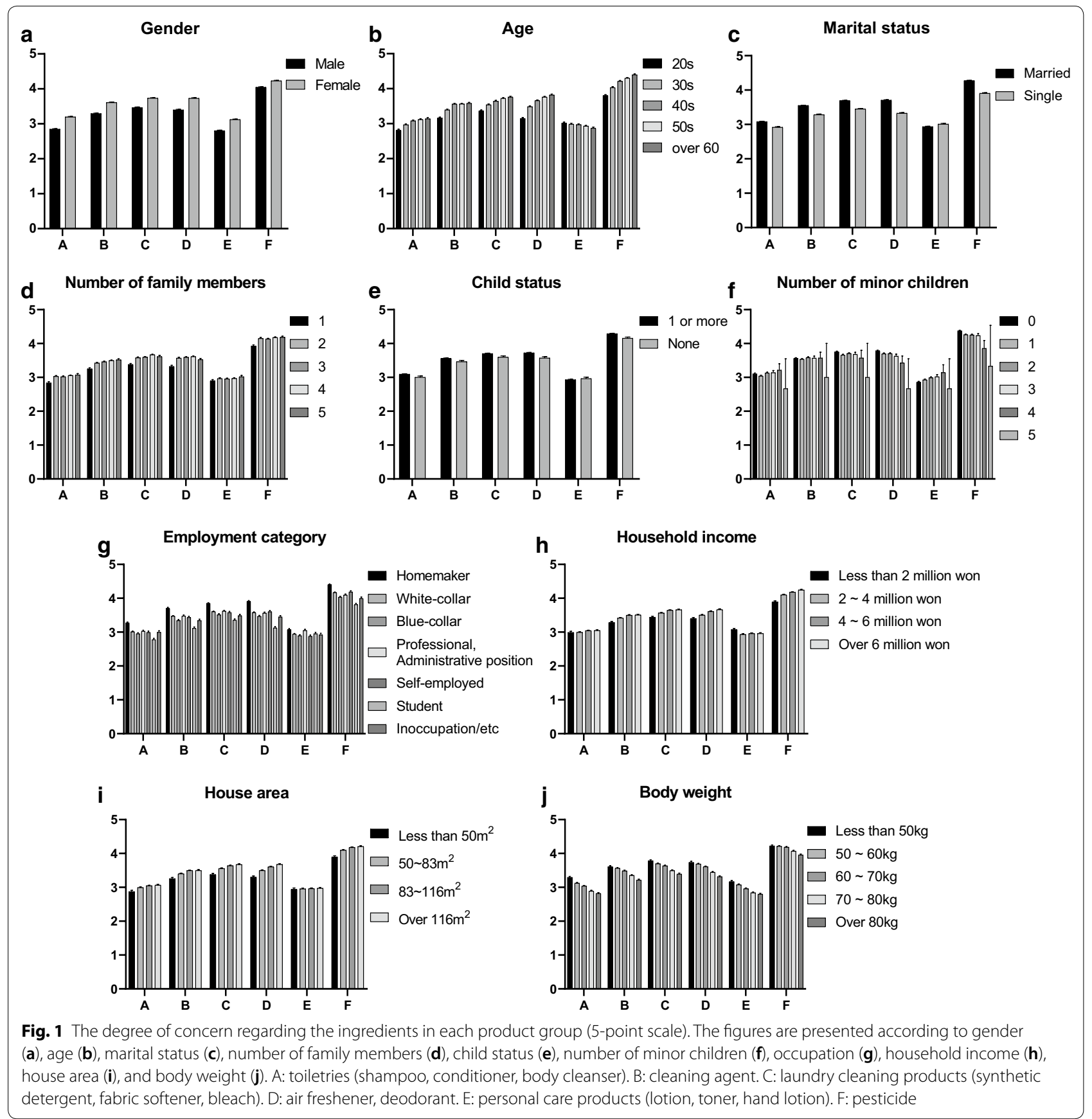

members, respondents with more than two family members expressed more concern about toiletries than people living alone $($ mean $=2.84)$ (Fig. 1d). When arranged according to employment category, in the case of homemakers, the scores were noticeably higher $($ mean $=3.27$ ); however there were no significant differences among the other occupations except students (mean $=2.78)($ Fig. $1 \mathrm{~g})$.

The degree of concern expressed regarding the substances in cleaning agents was higher among females $($ mean $=3.61)$ than males $($ mean $=3.29)($ Fig. 1a). Married participants $($ mean $=3.55)$ expressed a greater degree of concern than unmarried participants $($ mean $=3.47$ ) (Fig. 1c). When grouped according to employment category, the degree of concern regarding the substances in cleaning agents was highest in homemakers (mean $=3.71$ ), while students expressed the lowest degree of concern (mean =3.11) (Fig. 1g). Furthermore, only the groups with the lowest household income (mean $=3.29)$ (Fig. 1h) and those living alone $($ mean $=3.25)$ (Fig. 1d) indicated significantly lower concerns than other groups. 
For substances found in laundry cleaning products (synthetic detergents, fabric softeners, and bleaches), females (mean $=3.74$ ) expressed a greater degree of concern than males (mean =3.47) (Fig. 1a), while concerns were greater among married participants (mean $=3.69$ ) than unmarried participants (mean $=3.45$ ) (Fig. 1c). In addition, people in their twenties (mean $=3.37$ ) and thirties (mean $=3.54$ ) expressed lower degrees of concern than others (Fig. 1b). The group of respondents who lived alone expressed lower concern for laundry cleaning agents $($ mean $=3.38)$ than other groups (Fig. 1d). In terms of occupation, the highest degree of concern was expressed by homemakers (mean $=3.85$ ) (Fig. 1g).

For substances in air fresheners and deodorants, females expressed a greater degree of concern (mean $=3.73$ ) than males $($ mean $=3.40$ ) (Fig. 1a). Concern was also higher in married participants $($ mean $=3.71)$ than unmarried participants (mean =3.33) (Fig. 1c), while participants with children expressed a greater degree of concern $($ mean $=3.71)$ than participants without children $($ mean $=3.57)$ (Fig. 1e). Homemakers expressed the greatest concerns (mean $=3.91)$ in air fresheners and deodorants, while students indicated the lowest concern (mean =3.12) (Fig. 1g). Depending on the number of family members, people who lived alone indicated a low degree of concern $($ mean $=3.32)$ (Fig. 1d). In the case of household areas, larger household size was associated with a higher level of concern (Fig. 1i).

For personal care products, including lotions, toners, and hand lotions, females expressed more concern (mean $=3.12$ ) than males $($ mean $=2.80)$ (Fig. 1a). For the other five product groups, the degree of concern was greater in married participants than single participants. However, in the case of personal care products, concern was greater in single respondents $($ mean $=3.01$ ) than married respondents $($ mean $=2.93$ ) (Fig. 1c). Furthermore, for the other product groups, the degree of concern increased as the participants' age increased. By contrast, in the case of personal care products, younger participants tended to express more concern than older participants albeit non-significantly (Fig. 1b). Participants in their twenties expressed the highest degree of concern (mean $=3.02$ ) and those over 60 showed the lowest perceived concern (mean $=2.87)$.

For pesticides, the expressed concerns were greater than for any other chemical product group, with females expressing more concern (mean $=4.23)$ than males (mean $=4.05)$ (Fig. 1a). The degree of concern tended to increase with respondent age. Those in their twenties expressed the lowest degree of concern (mean $=3.80$ ), followed by participants in their thirties (mean $=4.03$ ), forties $($ mean $=4.21)$, fifties $($ mean $=4.30)$, and over 60 (mean $=4.40)$ (Fig. 1b). Married participants were more concerned $($ mean $=4.28)$ than unmarried participants (mean $=3.91)$ (Fig. 1c). Those living alone indicated lower concern about pesticides (mean $=3.93$ ) than other groups (Fig. 1d). Participants with children expressed more concern about the substances in pesticides (mean $=4.29)$ than participants without children (mean $=4.16)$ (Fig. 1e). Respondents' concern about pesticides was associated with larger houses, lower body weights, and greater household income (Fig. $1 \mathrm{~h}-\mathrm{j}$ ). In terms of occupation, the degree of concern expressed was highest in homemakers (mean $=4.40)$, followed by self-employed individuals $($ mean $=4.19)$, white-collar workers $($ mean $=4.17)$, professionals and administrative workers (mean $=4.09$ ), and blue-collar workers $($ mean $=4.03)$ (Fig. 1g).

\section{Mass media and consumer/environmental organizations were the favored information sources for determining the risk of chemicals in consumer products}

Figure 2 shows where people obtain and believe information about harmful substance and products. Four out of ten respondents indicated that mass media (TV, radio) was a reliable information source. Information from consumer/ environmental organizations (non-governmental organizations) and the product ingredient list were trusted by $36.8 \%$ and $30.3 \%$ of respondents, respectively. Information from packaging (29.8\%) and government sources (25.1\%) were the next most trusted information sources. Pictograms (i.e., hazard symbols) were trusted by $24.3 \%$ of participants. Very different results were reported in a German study [19], in which the hazard pictograms used in the "Classification, Labeling and Packaging" regulation were considered to be trustworthy information by $74.3 \%$ of respondents.

Figure 3 shows the trend in confidence by age class. As age increased, trust in mass media also increased (Fig. 3). Trust in consumer/environmental organizations tended to increase with age, while trust in product ingredient lists and pictograms decreased with age.

\section{Some respondents assumed there were no hazardous substances in certain consumer chemical products}

The survey participants were asked which product types they thought did not contain harmful substances. Nearly half of the participants $(47.3 \%)$ considered products made of natural materials and products with eco-friendly labeling (47.2\%) did not contain harmful substances (Fig. 4). Among the survey participants, 23.2\% believed that products for children did not contain harmful substances, and $9.5 \%$ of the respondents stated that products without harmful information (or pictograms) on the packaging are free of harmful substances. Furthermore, $2.4 \%$ of the participants believed that foreign products did not contain harmful substances. By contrast, $23.2 \%$ of the respondents assumed that none of the products were free from harmful substances. 

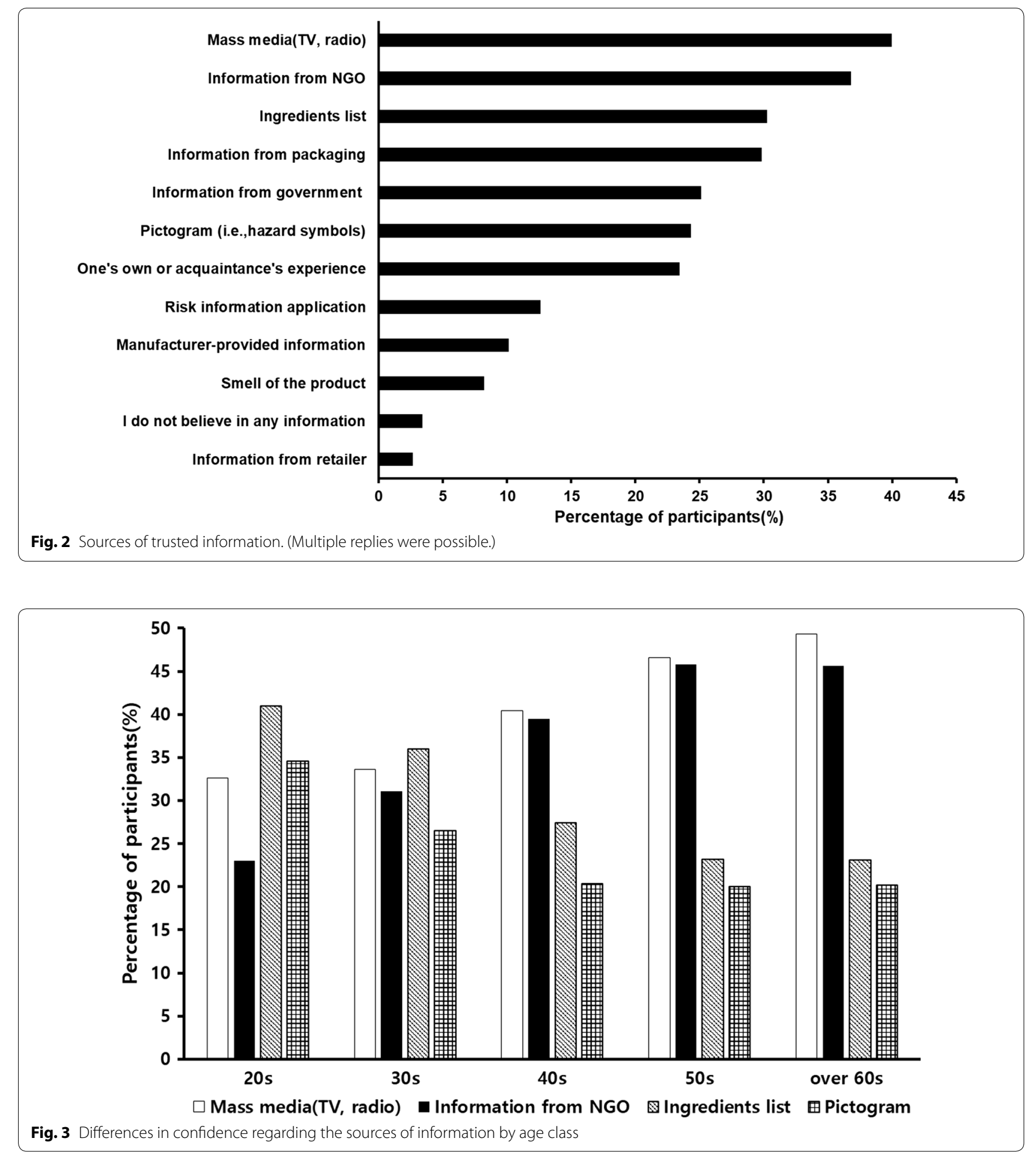

In a similar German study [19], some respondents did not recognize the presence of harmful substances in products with an ecolabel (36.1\%), natural personal care products $(35.7 \%)$, products without a hazard pictogram (11.0\%), and products for children (6.7\%). This result indicates that the respondents in our study were more unaware of the presence of harmful substance in products than the respondents in the German study. However, a similar percentage of respondents believed that there were no products that did not contain hazardous substances (20.1\% in the German study). 


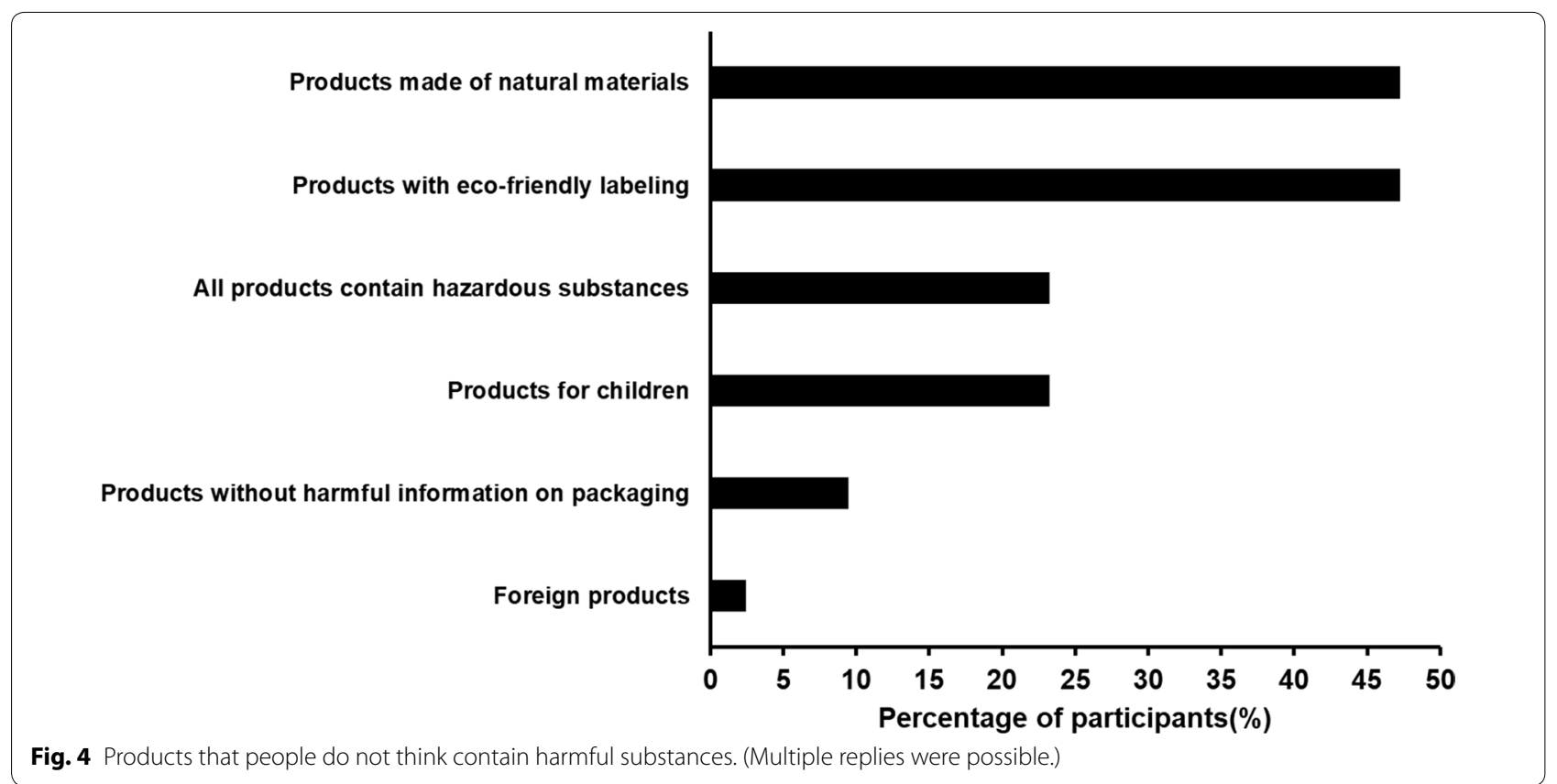

\section{Careful use of consumer chemical products} was the preferred strategy to reduce the risk The risk posed by harmful chemicals in consumer products can be controlled by reducing exposure. Therefore, participants were asked about their favored risk reduction strategy. Many respondents (47.5\%) indicated that they used certain products as little as possible (Fig. 5).
Moreover, $40.0 \%$ of participants confirmed that they read and followed the recommended application and safety instructions on the products. To reduce risk, $21.8 \%$ of participants wore gloves or masks when using chemical products. Slightly fewer participants $(20.7 \%)$ indicated that they would buy alternative products. Some respondents (12.7\%) stated that the amounts of

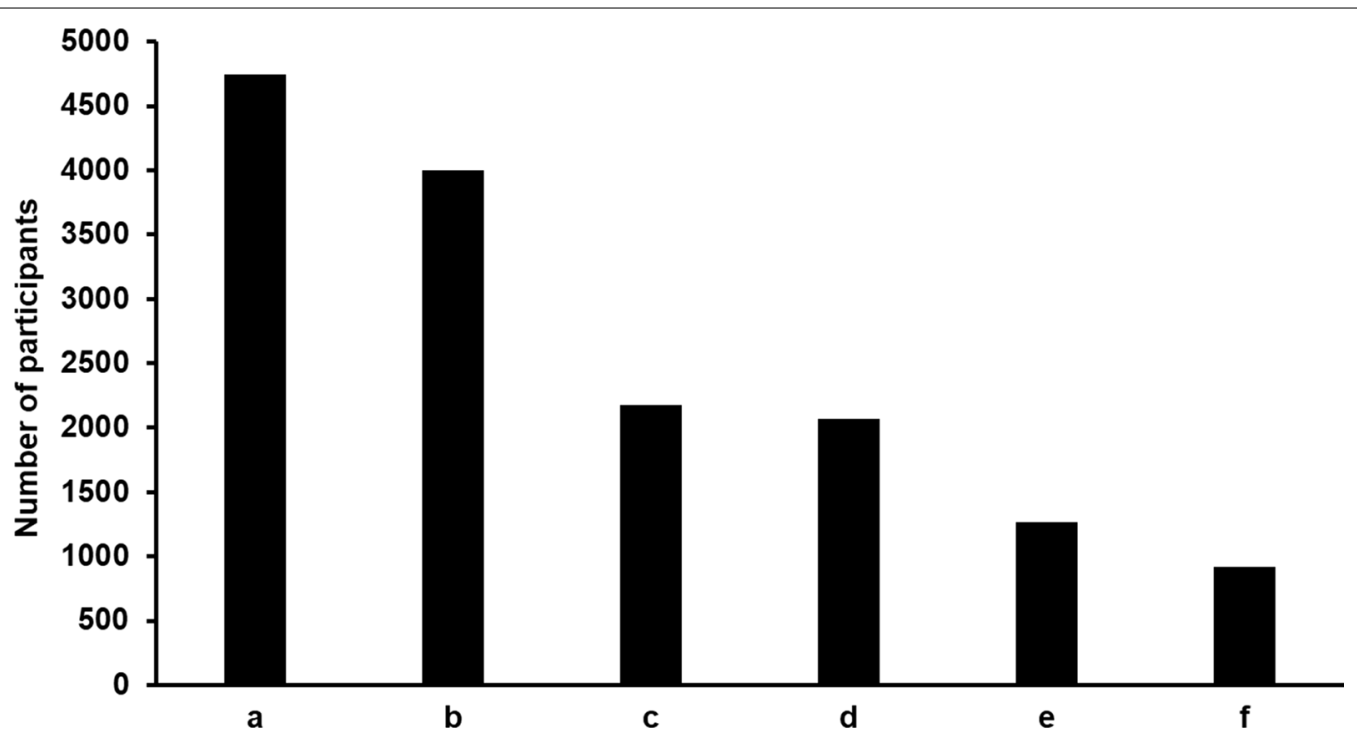

Fig. 5 Efforts to reduce harm caused by product use. a: I use the products as little as possible. b: I read the description on the packaging carefully and follow that. c: I wear gloves or mask. d: I will buy other products. e: The amounts that I use are so small that I believe the product does not have negative effects. f: I don't do anything. (Multiple replies were possible.) 
chemical products they used were so small that they believed the products would not have any negative effects. Finally, $9.2 \%$ of participants indicated that they used the products without taking any action to reduce exposure to potentially harmful chemicals.

\section{The manufacturer and retailer should be responsible} for reducing the use of harmful substances in consumer products

More than half of respondents (51.6\%) considered that the manufacturer and retailer should be responsible for reducing harmful substances in consumer chemical products (Fig. 6). Meanwhile, 38.7\% of participants thought that the government and legislators should carry

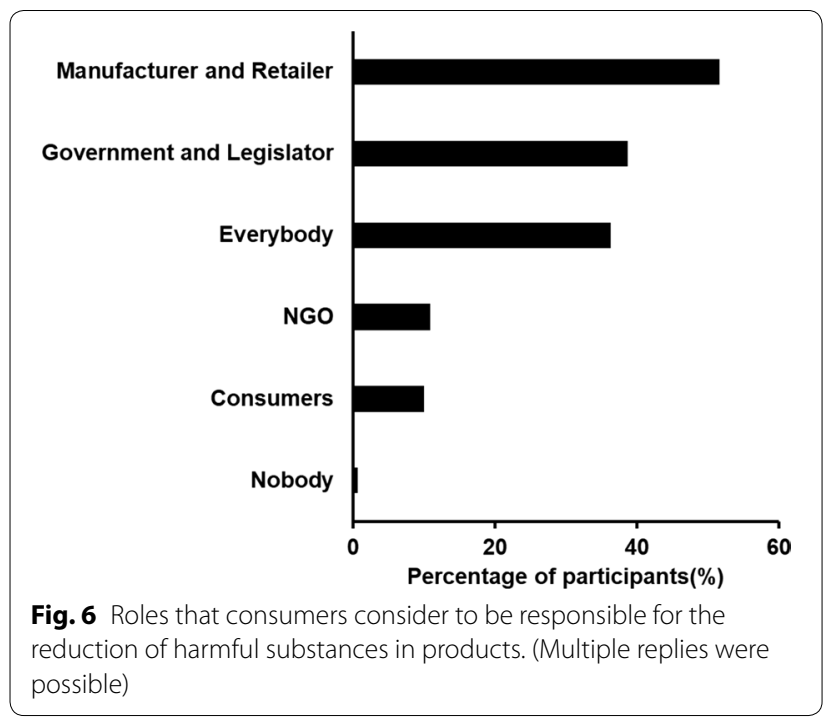

this responsibility. In addition, $36.3 \%$ of respondents considered everybody to have a responsibility, while other respondents targeted consumer/environmental organizations $(10.8 \%)$ and consumers $(10.0 \%)$.

\section{People want accurate and definite information}

Survey participants were asked what they wanted from a tool (smartphone application) that would provide information about harmful substances in consumer chemical products (Fig. 7). The majority of respondents (66.3\%) wanted access such as an application to obtain accurate information. Figure 7 shows that consumers wanted information about the extent to which each substance is harmful (carcinogenic, mutagenic, toxic, etc.) (55.7\%). Furthermore, respondents wanted information that is simple, brief (33.7\%), and updated quickly and regularly (33.5\%). Some respondents also wanted the system to be managed by the government (23.4\%).

\section{Many people did not know about the potential to request information disclosure}

Figure 8 shows a survey of consumer perceptions of the information disclosure procedure of $\mathrm{K}-\mathrm{REACH}$ regarding the chemicals included in consumer products. Most respondents $(62.1 \%)$ were not aware of the possibility to make an information disclosure request (Fig. 8a). About $37 \%$ of each occupation responded that they were aware about information disclosure requests, while $47.0 \%$ of special or administrative occupations were aware of them (Fig. 8b).

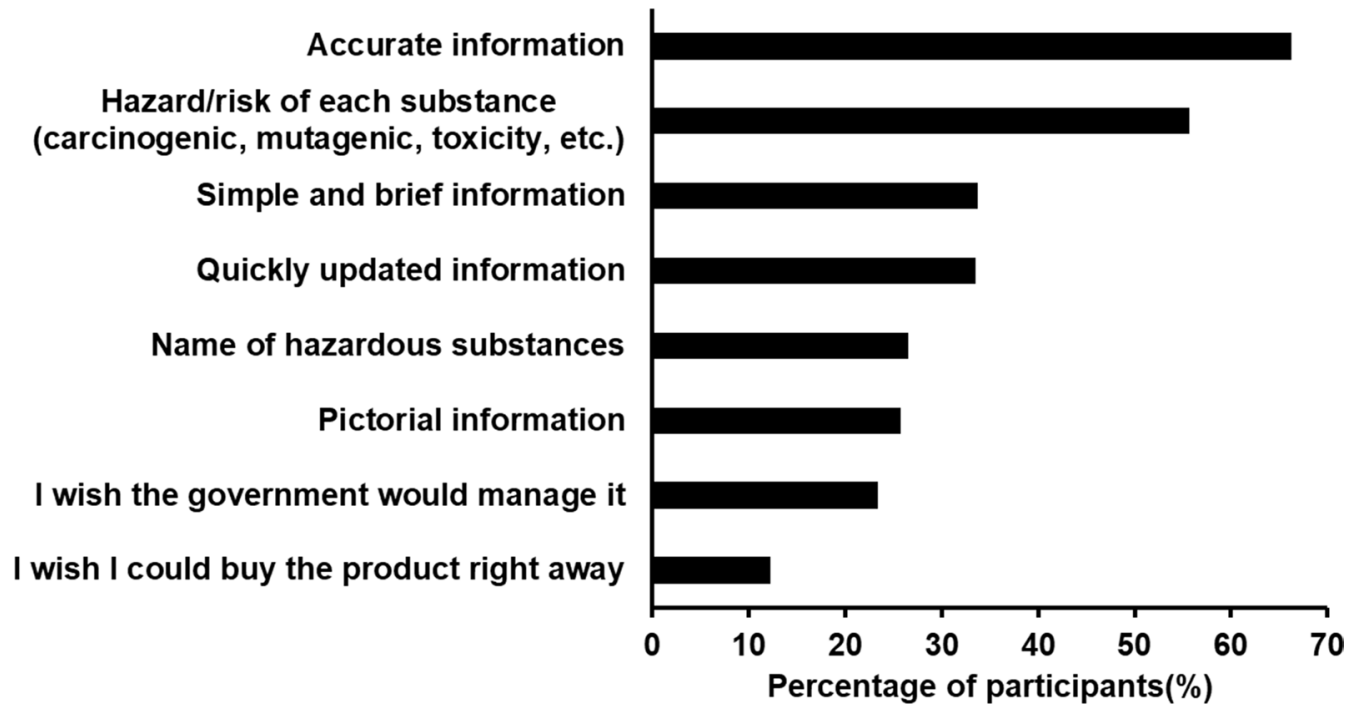

Fig. 7 Requirements for risk information systems (application). (Multiple replies were possible.) 


\section{a}

Percentage of participants(\%)

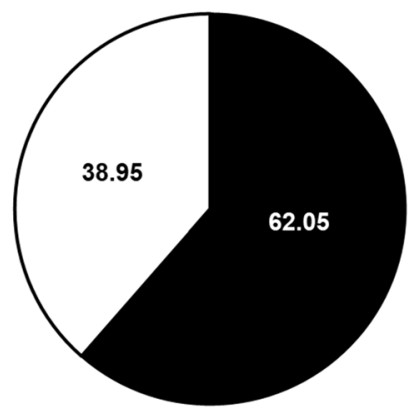

I didn't recognize that. $\quad$ l recognize that

\section{b}

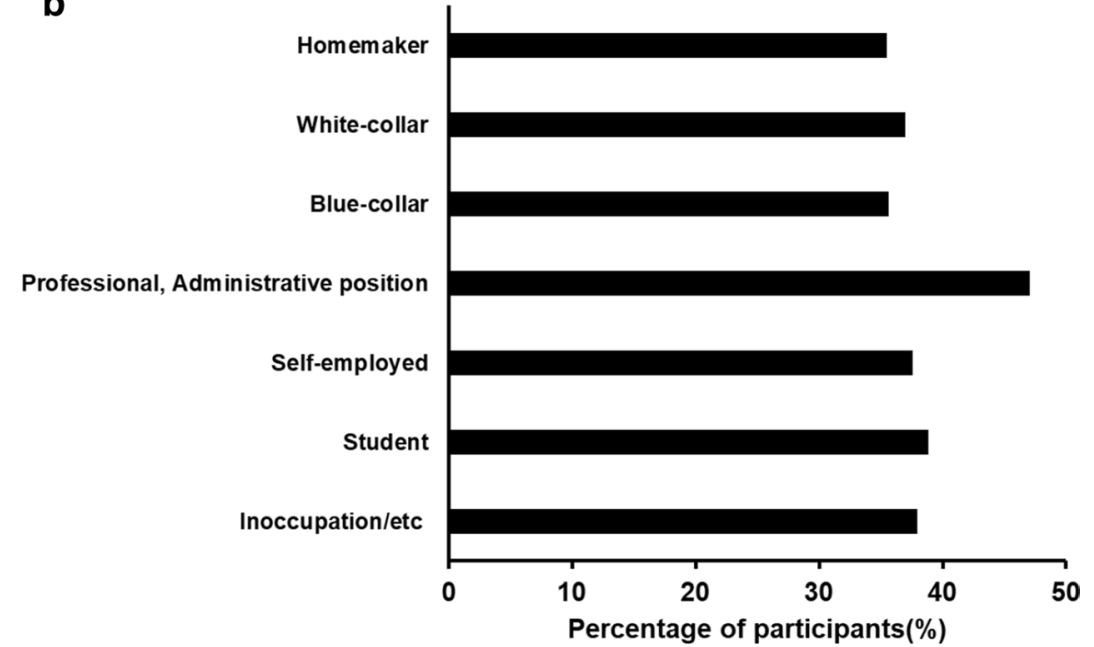

Fig. 8 Recognition of the availability of information disclosure requests for product ingredients by the total percentage of participants (a) and by occupation (b)

The main consideration when purchasing consumer chemical products was safety

Participants were asked what their most important consideration was when purchasing a product (Fig. 9). The most frequent answers were safety (68.4\%) and efficiency (67.1\%). Less than $50 \%$ of respondents $(46.9 \%)$ indicated price as an important consideration, followed by manufacturer (brand) (36.3\%).

\section{Discussion}

Differences in the perception of risks associated with consumer products by demographic characteristics As shown in Fig. 1, concerns about the ingredients of consumer chemical products vary depending on demographic characteristics. In all product categories, as reported previously [20], women rated risks higher than men. Homemakers were more concerned than other occupational groups because they may use more chemical products than those in other occupations. Concern about the ingredients of consumer products was greater in those with lower body weights. Because exposure is evaluated by dividing the amount of material by body weight [21], people with lower body weight are exposed to more chemicals per unit weight. Furthermore, for all product groups, people who own larger houses perceived higher risks. Respondents living alone rated risks as higher than those living together. Of the five product groups (toiletries, cleaning agents, laundry cleaning

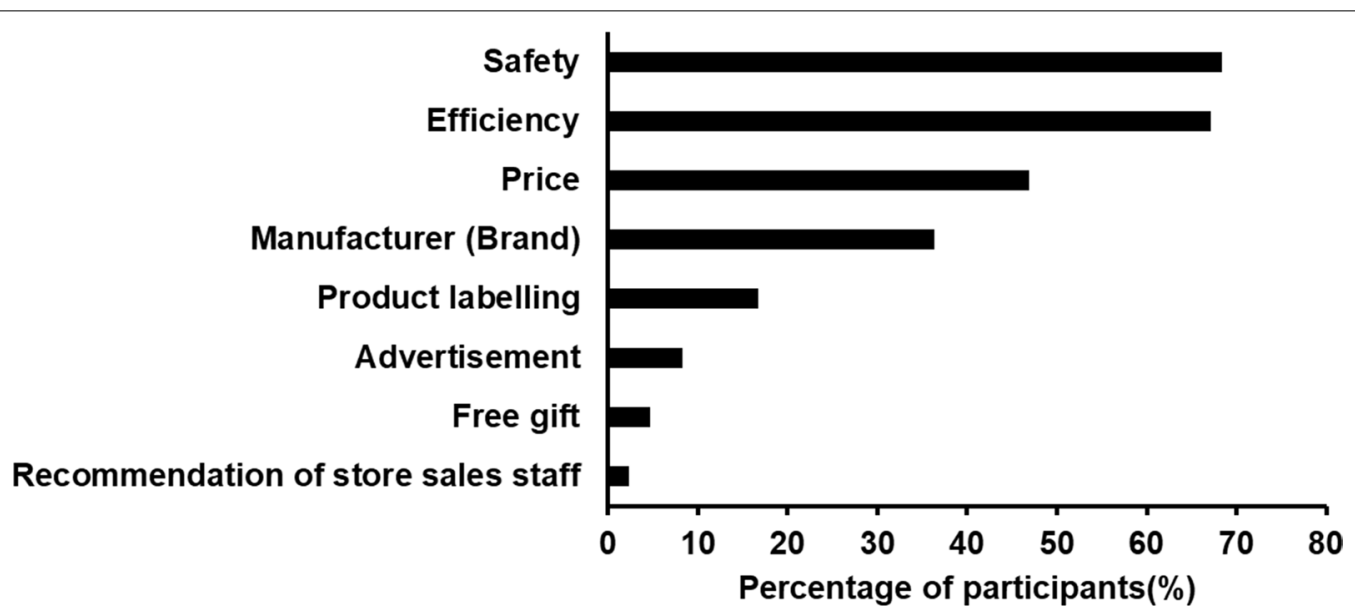

Fig. 9 Most important consideration when purchasing a product. (Multiple replies were possible.) 
products, air fresheners/deodorants, pesticides), except for personal care products, respondents who were older, married, had children, or had a higher household income tended to value high levels of concern for ingredients. Personal care products tended to differ from other product groups in terms of age, marital status, child status, and household income. This is thought to be because young, unmarried and childless people are more dedicated to personal care. Those with less information about chemical risks included men, people who were not homemakers, heavier people, and people with smaller houses. Overall, we believe that the scope of education should be expanded to include instructions on harmful substances.

\section{Consumer misconceptions regarding safety and risk}

Lack of knowledge and misconceptions about harmful chemicals or products can lead to unsafe behavior and exposure to harmful substances [18]. The respondents in this study also indicated many misconceptions. Some respondents believed that products made from natural materials and products with eco-friendly labeling did not contain harmful chemicals (Fig. 4). Contrary to their beliefs, natural materials can pose risks because of natural toxins [22]. Furthermore, in Korea, eco-friendly labeling does not indicate that a product does not pose health risks. This is because the Republic of Korea only labels products that satisfy any of the following seven criteria compared to other products or services for the same purpose: (1) improves resource circulation, (2) saves energy, reduces (3) global or (4) regional environmental pollution, (5) reduces harmful substances, (6) reduces living environmental pollution, and (7) reduces noise or vibrations throughout all phases of production, distribution, use, disposal, etc. People can check the Korea Institute of Environmental Industry and Technology-Environmental Labeling website [23] to find out why a particular product might be labeled. However, it is not possible to determine whether harmful substances were reduced just during the production process or in the product itself. Furthermore, even when the content of the harmful chemical substance in a product is low, the label only indicates that it is lower than that of similar products, so the product may still carry some risk. Similarly, the European Union ecolabel for non-food products does not mean that a product is free of harmful substances [24]. Furthermore, in the case of the organic mark, there is no organic certification system for non-food items in Korea, and organic labels on consumer products are not verified. In other words, there is currently no system that can determine whether a product poses a risk just by looking at its label. There are many tools to provide risk information in other countries, such as the German smartphone application called 'ToxFox [25]'. ToxFox indicates whether a personal care product contains endocrine disruptors, and also helps consumers to ask manufacturers for information about chemicals in consumer chemical products under REACH. Denmark has an application called 'Kemiluppen [26]', which provides information on chemical products that contain endocrine disruptor, allergenic substances, etc., under various criteria. The website/application called 'GoodGuide [27]' is another tool that allows consumers to retrieve evaluations of the health, environmental, and social impacts of consumer products. However, there are no tools (e.g., applications or websites) providing trustworthy risk information in Korea. As such, the government should require companies to disclose substances and their concentrations. Based on these data, experts could then calculate potential exposure, and overall risk of the product. A tool providing this risk information to the public could then be developed.

Finally, most respondents indicated that their preferred strategy to reduce risk was to use the product as little as possible (Fig. 5). However, this risk avoidance strategy is only possible when consumers are aware that a consumer product contains hazardous substances. Therefore, we believe that it is vital to properly inform consumers about the harmful substances in their daily chemical products.

\section{Effective risk communication to consumers}

Our survey showed that consumers cannot accurately distinguish harmful from safe products. Furthermore, the results of this study suggest that consumers want correct and clear information delivery systems (Fig. 7). Also, many respondents did not know that they can make an information disclosure request under $\mathrm{K}-\mathrm{REACH}$ (Fig. 8). K-REACH [7] and the Act on Safety Control of Consumer Chemical Products and Biocides (Section 1, Article 30) [9] include clauses about providing information regarding chemical substances in products or biocidal products. However, information relating to business secrets pursuant to business proprietary information as defined in Section 2, Article 2 of the Unfair Competition Prevention and Trade Secret Protection Act, such as the composition and amount of chemicals in such products, is not included in the information that must be provided $[8,9]$. Consequently, companies are using this Act to refuse to provide information to consumers [28, 29].

The European Rapid Alert system for products, called RAPEX, is a system in the European Union that notifies consumers of products that are not compliant with legal standards and pose serious health or safety risks [30]. It is updated weekly with photographs, brands and product names, and harm information about products online. In Korea, the Ministry of Environment also provides information on products containing restricted substances or violating safety standards [31]. However, consumers have 
to find information in press release section of the website, which may be inconvenient those for those who only want information of substandard products and not other information. As shown in Fig. 2, consumers only have about $25 \%$ confidence in the information provided by the government. Hence, we believe that there is a need for a system that makes consumers aware of substandard products (products to be recalled), and that this system should be reliable and easily accessible.

\section{Study limitations}

In this study, people were not provided the exact definitions of words that could potentially be difficult to understand, such as consumer products, harmful chemicals, and information disclosure request. Therefore, the interpretation of the words used in the survey could vary among respondents, resulting in potentially inaccurate results. The response rate of a similar German study was very different to that of our study, with the response rate of our study being so low that direct comparison may be difficult. In addition, as mentioned in the methods, this survey contained questions regarding the usage pattern of products. Therefore, the full questionnaire was very long, which could induce fatigue, leading to insincere responses from respondents.

\section{Conclusion}

There is a growing fear of chemicals among consumers; therefore, we conducted a survey of consumer awareness of the risks posed by consumer chemical products to better meet consumer needs. Many people still misunderstand the risks associated with chemical products, and assume that the responsibility for risk reduction and safety lies entirely with manufacturers and retailers. Because the information that is most trusted is provided by the mass media, the media should be used to communicate accurate information about harmful chemicals in consumer products and the ways to avoid harm. In addition, the potential for consumers to make an information disclosure request should be better publicized. These results are significant given that this was the first large $(10,000$ respondents) survey of consumer perception regarding consumer chemical products in Korea.

\section{Supplementary information}

Supplementary information accompanies this paper at https://doi. org/10.1186/s12302-019-0278-x.

Additional file 1. Additional figure and tables.

Additional file 2. Consumer Perception Survey questionnaire originally in Korean translated to English.
Abbreviations

K-REACH:The Act on the Registration and Evaluation of Chemical Substances; REACH: The European Registration, Evaluation, Authorization and Restriction of Chemicals.

\section{Acknowledgements}

Not applicable.

\section{Authors' contributions}

AYK, EL, SK and YJL developed and designed the basic ideas of the study. SS, $\mathrm{YU}, \mathrm{KOC}, J \mathrm{C}, \mathrm{EJH}, \mathrm{QB}$, and TC made the questionnaire. SS, YU, JL, QB, DIL performed the data analysis. SS, JL, and QB were major contributors in writing the manuscript. All authors read and approved the final manuscript.

\section{Funding}

This research was supported by Research Program to Solve Social Issues of the National Research Foundation of Korea (NRF) funded by the Ministry of Science and ICT (No. NRF-2017M3C8A6091777).

\section{Availability of data and materials \\ Not applicable.}

Ethics approval and consent to participate

Not applicable.

\section{Consent for publication}

Not applicable.

\section{Competing interests}

The authors declare that they have no competing interests.

\begin{abstract}
Author details
1 Department of Integrated Bioscience and Biotechnology, College of Life Science, Sejong University, Kwangjingu, Kunjadong, Seoul 05006, South Korea. ${ }^{2}$ Korea Consumer Foundation, SEOUL YWCA BId. \#701, 20, Myungdong11 gil, Jung-gu, Seoul, South Korea. ${ }^{3}$ Korea National Council of Consumer Organizations, SEOUL YWCA Bld. \#701, 20, Myungdong1 1 gil, Jung-gu, Seoul, South Korea. ${ }^{4}$ Korean Woman's Federation for Consumer, Sangdong Bld. \#603, Namdaemun-ro 30, Jung-gu, Seoul, South Korea. ${ }^{5}$ Institute of Indian Studies, Korea, \#1103, 6, Teheran-ro 52-gil, Gangnam-gu, Seoul, South Korea. ${ }^{6}$ Hanyang University Law School, 222 Wangsimni-ro, Seongdong-gu, Seoul, South Korea. ${ }^{7}$ Department of Food Science and Biotechnology, Sejong University, Kwangjingu, Kunjadong, Seoul 05006, South Korea. ${ }^{8}$ Department of Business Administration, Sejong University, Kwangjingu, Kunjadong, Seoul 05006, South Korea.
\end{abstract}

Received: 9 September 2019 Accepted: 5 December 2019

Published online: 21 December 2019

\section{References}

1. Park J-H, Kim HJ, Kwon G-Y et al (2016) Humidifier disinfectants are a cause of lung injury among adults in South Korea: a community-based case-control study. PLoS ONE 11(3):e0151849

2. Paek D, Koh Y, Park D-U et al (2015) Nationwide study of humidifier disinfectant lung injury in South Korea, 1994-2011 Incidence and doseresponse relationships. Ann Am Thoracic Society 12(12):1813-1821

3. Special Commission on Social Disaster Investigation (2019) 2019 Explanation of humidifier disinfectant disaster. http://socialdisasterscommission go.kr/. Accessed 29 Mar 2019. (in Korean)

4. Kim S (2017) Reviewing the Korean episodes of environmental chemicals in summer 2017. Korean J Public Health 54(2):3-12 (in Korean)

5. Hartings MR, Fahy D (2011) Communicating chemistry for public engagement. Nat Chem 3(9):674

6. Francl M (2013) How to counteract chemophobia. Nat Chem 5(6):439

7. The Act on the Registration and Evaluation, etc. of Chemicals. http:// www.law.go.kr/\%EB\%B2\%95\%EB\%A0\%B9/\%ED\%99\%94\%ED\%95\%99\%E B\%AC\%BC\%EC\%A7\%88\%EC\%9D\%98\%20\%EB\%93\%B1\%EB\%A1\%9D\%20 \%ЕВ\%B0\%8F\%20\%ED\%8F\%89\%EA\%B0\%80\%20 
\%EB\%93\%B1\%EC\%97\%90\%20\%EA\%B4\%80\%ED\%95\%9C\%20 \%EB\%B2\%95\%EB\%A5\%A0. Accessed 14 Oct 2019. (in Korean)

8. Enforcement Rules of The Act on the Registration and Evaluation, etc. of Chemicals. http://www.law.go.kr/LSW//lumLsLinkPop.do?lspttninfS $\mathrm{eq}=123243 \& \mathrm{chrClsCd}=010202$. Accessed 14 Oct 2019. (in Korean)

9. The Act on Safety Control of Consumer Chemical Products and Biocides. http://www.law.go.kr/\%EB\%B2\%95\%EB\%A0\%B9/\%EC\%83\%9D\%ED\%99\% 9C\%ED\%99\%94\%ED\%95\%99\%EC\%A0\%9C\%ED\%92\%88\%EB\%B0\%8F\%EC \%82\%B4\%EC\%83\%9D\%EB\%AC\%BC\%EC\%A0\%9C\%EC\%9D\%98\%EC\%95\% 88\%EC\%A0\%84\%EA\%B4\%80\%EB\%A6\%AC\%EC\%97\%90\%EA\%B4\%80\%E D\%95\%9C\%EB\%B2\%95\%EB\%A5\%A0/(15511,20180320). Accessed 14 Oct 2019. (in Korean)

10. Regulation (EC) No 1272/2008 of the European parliament and of the council of 16 December 2008 on classification, labelling and packaging of substances and mixtures, amending and repealing Directives 67/548/ EEC and 1999/45/EC, and amending Regulation (EC) No 1907/2006. https ://eur-lex.europa.eu/legal-content/EN/TXT/?uri=CELEX\%3A32008R1272. Accessed 29 Mar 2019

11. Chemical Abstracts Service (2015) CAS assigns the 100 millionth CAS registry Number ${ }^{\circledR}$ to a substance designed to treat acute myeloid leukemia. Chemical Abstracts Service, Columbus

12. Park JY, Lee K, Hwang Y et al (2015) Determining the exposure factors of personal and home care products for exposure assessment. Food Chem Toxicol 77:105-110

13. Kortenkamp A, Faust M (2018) Regulate to reduce chemical mixture risk Science 361(6399):224-226

14. Csiszar SA, Meyer DE, Dionisio KL et al (2016) Conceptual framework to extend life cycle assessment using near-field human exposure modeling and high-throughput tools for chemicals. Environ Sci Technol 50(21):11922-11934

15. Jolliet O, Ernstoff AS, Csiszar SA et al (2015) Defining product intake fraction to quantify and compare exposure to consumer products. ACS Publications, Columbus

16. Phillips KA, Wambaugh JF, Grulke CM et al (2017) High-throughput screening of chemicals as functional substitutes using structure-based classification models. Green Chem 19(4):1063-1074
17. Tao M, Li D, Song R et al (2018) OrganoRelease-A framework for modeling the release of organic chemicals from the use and post-use of consumer products. Environ Pollut 234:751-761

18. Selin H (2009) Managing hazardous chemicals: longer-range challenges. Boston University Creative Services, The Pardee Papers

19. Hartmann S, Klaschka U (2017) Interested consumers' awareness of harmful chemicals in everyday products. Environ Sci Eur 29(1):29

20. Hitchcock JL (2001) Gender differences in risk perception: broadening the contexts. Risk 12:179

21. Comiskey D et al (2015) Novel database for exposure to fragrance ingredients in cosmetics and personal care products. Regul Toxicol Pharmacol 72(3):660-672

22. Seeff LB (2007) Herbal hepatotoxicity. Clin Liver Dis 11(3):577-596

23. Korea Institute of Environmental Industry and Technology-Environmental Labeling website. http://el.keiti.re.kr/service/index.do. Accessed 14 Oct 2019. (in Korean)

24. Regulation on the EU ecolabel (EC) 66/2010. http://eur-lex.europa.eu/ legal-content/EN/TXT/?uri=CELEX:32010R0066. Accessed 10 October 2019

25. https://www.bund.net/themen/chemie/toxfox/. Accessed 14 Oct 2019. (in German)

26. https://kemi.taenk.dk/bliv-groennere/kemiluppen-tjek-din-personlige -pleje-uoensket-kemi. Accessed 14 Oct 2019. (in Danish)

27. https://www.goodguide.com/\#/. Accessed 14 Oct 2019

28. http://thel.mt.co.kr/newsView.html?no=2019050317278289793. Accessed 14 Oct 2019. (in Korean)

29. http://www.busan.com/view/busan/view.php?code $=201904291918097$ 2474. Accessed 14 Oct 2019. (in Korean)

30. http://www.ec.europa.eu/rapex. Accessed 14 Oct 2019

31. Korea Ministry of Environment. me.go.kr. Accessed 14 Oct 2019. (in Korean)

\section{Publisher's Note}

Springer Nature remains neutral with regard to jurisdictional claims in published maps and institutional affiliations.

\section{Submit your manuscript to a SpringerOpen ${ }^{\circ}$ journal and benefit from:}

- Convenient online submission

- Rigorous peer review

- Open access: articles freely available online

- High visibility within the field

- Retaining the copyright to your article

Submit your next manuscript at springeropen.com 